九州大学学術情報リポジトリ

Kyushu University Institutional Repository

\title{
An Application of Bondi K-Factor to the Preliminary Investigation into Some Natural Phenomena
}

Shimojo, Masataka

Deparatment of Bioresource Sciences, Faculty of Agriculture, Kyushu University

https://doi.org/10.5109/1467633

出版情報：九州大学大学院農学研究院紀要. 59 (2)，pp. 301-303，2014-08-29. Faculty of Agriculture, Kyushu University バージョン :

権利関係 : 


\title{
An Application of Bondi K-Factor to the Preliminary Investigation into Some Natural Phenomena
}

\author{
Masataka SHIMOJO* \\ Laboratory of Regulation in Metabolism and Behavior, Division of Animal and Marine Bioresource Sciences, \\ Department of Bioresource Sciences, Faculty of Agriculture, \\ Kyushu University, Fukuoka 812-8581, Japan \\ (Received April 25, 2014 and accepted May 12, 2014)
}

\begin{abstract}
This study was designed to apply Bondi K-factor to the preliminary investigation into some natural phenomena. Hypotheses (A) (D) were suggested. (A) The mathematical application of the infinite velocity $(v \rightarrow \infty)$ to Bondi K-factor collapsed it and gave the imaginary unit $(\boldsymbol{i})$, wave function and its conjugate complex. (B) The infinite velocity giving $\boldsymbol{i}$ was associated with the simultaneous existence at different places, which might look like a potential state that was described using the wave function and its conjugate complex. (C) The mathematical recovery of Bondi K-factor from $\boldsymbol{i}$ was associated with the collapse of the wave function into the real number. (D) Bondi $\mathrm{K}$-factor gave a simplified model of the space $(-c<v<c, c$ $=$ speed of light in vacuum). The space size was 0 when $v=-c$. If $v$ began to increase from $-c$, then the newborn tiny space showed a rapid expansion. This was followed by the decrease of the expansion force of the space. This decrease continued until the inflection point that occurred at $v=-c / 2$. If $v$ took values higher than $-c / 2$ by going across the inflection point, then there occurred an acceleration of the space expansion. This acceleration continued, and the space size reached $\infty$ when $v=c$. This study suggested a hypothesis that Bondi K-factor had something to do with some natural phenomena.
\end{abstract}

Key words: Bondi $\mathrm{K}$-factor, exponential function, imaginary unit, infinite velocity, space

\section{INTRODUCTION}

Although engaged in the ruminant feed science, why I am interested in Bondi $\mathrm{K}$-factor (Bondi, 1964) is that this factor is equal to exponential function (Lavenda, 2000). Exponential function is used for the basic growth analysis of the individual plant (Blackman, 1919) and animal (Brody, 1945), but Bondi K-factor is an educational tool to teach special relativity (Bondi, 1964). In spite of this big difference between them, they are connected using the equality sign in the real number world. When extended to the complex number world, exponential function describes the wave phenomenon. However, Bondi $\mathrm{K}$-factor is defined in the real number world and therefore is prohibited from extending to the complex number world. Nevertheless, some reports (Shimojo, 2011a, 2011b; Shimojo and Nakano, 2013a, 2013b; Shimojo, 2014) suggested a hypothesis that the mathematical application of the infinite velocity to Bondi $\mathrm{K}$-factor collapsed it into the imaginary unit. Does this mathematical operation of Bondi $\mathrm{K}$-factor give the wave phenomenon like complex exponential function? It needs further investigation. In addition, what does the equality between Bondi $\mathrm{K}$-factor and exponential function mean? Does this phenomenon have something to do with natural phenomena in the real number world?

This study was designed to apply Bondi K-factor to the preliminary investigation into some natural phenom-

* E-mail: mshimojo@agr.kyushu-u.ac.jp

Part of this study was conducted at Agri-Bio Research Laboratory on Ito Campus, Kyushu University, Motooka, Fukuoka 819-0395 ena.

\section{APPLICATIONS OF BONDI K-FACTOR TO SOME NATURAL PHENOMENA}

Mathematical collapse of Bondi K-factor into the imaginary unit

Bondi K-factor (Bondi, 1964) is given by

$$
\sqrt{\frac{1+v / c}{1-v / c}},
$$

where $c=$ speed of light in vacuum, $v=$ velocity of matter, $0 \leq v<c$.

Bondi $\mathrm{K}$-factor follows the calculation rules of real numbers under the condition of $0 \leq v<c$. Therefore, the mathematical application of the infinite velocity $(v \rightarrow \infty)$ to Bondi $\mathrm{K}$-factor collapses it and gives the imaginary unit $(\boldsymbol{i})$, wave function and its conjugate complex,

$$
\lim _{v \rightarrow \infty}\left(\sqrt{\frac{1+v / c}{1-v / c}}\right),
$$

$$
\begin{aligned}
& =\lim _{\boldsymbol{v} \rightarrow \infty}\left(\sqrt{\frac{c / v+1}{c / v-1}}\right) \\
& =\sqrt{-1} \\
& =\boldsymbol{i}, \\
& =\frac{\psi(x, t)-\psi^{*}(x, t)}{2 A \sin (x, t)},
\end{aligned}
$$


where

$$
\begin{aligned}
& \psi(x, t)=A \exp (\boldsymbol{i}(k x-\omega t)), \\
& \psi^{*}(x, t)=A \exp (-\boldsymbol{i}(k x-\omega t)), \\
& \sin (x, t)=\sin (k x-\omega t) .
\end{aligned}
$$

The infinite velocity gives the infinite distance, but it is impossible to observe this phenomenon. An alternative interpretation of expressions (2) (7) seems to suggest a hypothesis that the infinite velocity is associated with the simultaneous existence at different places. This might look like a potential state that is described using the wave function and its conjugate complex.

The imaginary space $(\boldsymbol{i} x)$ and imaginary time $(\boldsymbol{i} t)$ in expressions (5) and (6) seem to be hypothetically given by the mathematical application of the infinite velocity to real time $(t)$ and real space $(x)$,

$$
\begin{aligned}
& x^{\prime}=\frac{x-v t}{\sqrt{1-(v / c)^{2}}}=\frac{c x / v-c t}{\sqrt{(c / v)^{2}-1}} \rightarrow \boldsymbol{i} c t, \\
& t^{\prime}=\frac{t-v x / c^{2}}{\sqrt{1-(v / c)^{2}}}=\frac{c t / v-x / c}{\sqrt{(c / v)^{2}-1}} \rightarrow \frac{\boldsymbol{i} x}{\mathrm{c}} .
\end{aligned}
$$

Do expressions (8) and (9) seem to suggest a hypothesis that the space-time replacement between the real number world and the complex number world influences the interpretation of the wave function?

\section{Mathematical recovery of Bondi K-factor from the imaginary unit}

If the state of $v=0$ is obtained, then there is a recovery of Bondi $\mathrm{K}$-factor from the imaginary unit,

$$
\frac{\psi(x, t)-\psi^{*}(x, t)}{2 A \sin (x, t)}=\boldsymbol{i} \rightarrow \sqrt{\frac{1+0 / c}{1-0 / c}}=1
$$

By the way, does this seem to suggest a hypothesis that the mathematical process in expression (10) has something to do with that of expression (11)?

$$
|\psi(x, t)|^{2}=\psi(x, t) \cdot \psi^{*}(x, t)=A^{2} .
$$

If so, do expressions (10) and (11) seem to suggest a hypothesis that the wave function collapses into the real number?

\section{Hypotheses suggested from the equality between Bondi K-factor and exponential function}

Bondi $\mathrm{K}$-factor is equal to exponential function (Lavenda, 2000),

$$
\sqrt{\frac{1+v / c}{1-v / c}}=\exp (\theta)
$$

where $-c<v<c,-\infty<\theta<\infty$.

Expression (12) seems to suggest a hypothesis that the exponential increase is a relativistic effect, and vice versa. If Bondi $\mathrm{K}$-factor is hypothetically regarded as a simplified model of the space, then this seems to suggest hypotheses (I) (IV). (I) I examine the space expansion under the condition that $v$ is increased from $-c$ to $c$. If $v$ begins to increase from $-c$, then the newborn tiny space shows a rapid expansion. (II) This is followed by the decrease of the expansion force of the space. This decrease continues until the inflection point that occurs at $v=-c / 2$. (III) If $v$ takes values higher than $-c / 2$ by going across the inflection point, then there occurs an acceleration of the expansion of the space. This acceleration continues, and the space size reaches $\infty$ when $v=c$. (IV) If $v=0$ and there is no further change in $v$, then the space size is kept constant.

If expression (12) is transformed as follows, then there appears a term (14) that interacts with the expansion of a space model (15) in order to conserve an invariant (13) mathematically,

$$
\begin{aligned}
& \left(\sqrt{\frac{1+v / c}{1-v / c}}\right) \exp \left(\ln \left(\sqrt{\frac{1-v / c}{1+v / c}}\right)\right)=1, \\
& \exp \left(\ln \left(\sqrt{\frac{1-v / c}{1+v / c}}\right)\right), \\
& \sqrt{\frac{1+v / c}{1-v / c}} .
\end{aligned}
$$

Expressions (13) (15) seem to suggest hypotheses (i) (iv). (i) If $v=-c$, then the space size (15) $=0$ and the term $(14)=\infty$. (ii) Does the space expand its size by the use of the energy coming from the term? (iii) If $v=\mathrm{c}$, then the space size $=\infty$ and the term $=0$. (iv) Are these singularities (i) and (iii) also under the mathematical control of the invariant (13)?

The mathematical application of the infinite velocity to expression (13) gives

$$
\begin{aligned}
& \lim _{\boldsymbol{v} \rightarrow \infty}\left(\left(\sqrt{\frac{1+v / c}{1-v / c}}\right) \exp \left(\ln \left(\sqrt{\frac{1-v / c}{1+v / c}}\right)\right)\right) \\
& =(\boldsymbol{i}) \exp (\ln (\boldsymbol{i})) \\
& =-1 \\
& \mid \lim _{\boldsymbol{v} \rightarrow \infty}\left(\left.\left(\sqrt{\frac{1+v / c}{1-v / c}}\right) \exp \left(\ln \left(\sqrt{\frac{1-v / c}{1+v / c}}\right)\right)\right|^{2}=1\right.
\end{aligned}
$$

where $\boldsymbol{i}$ = imaginary unit

Does the square calculation in expression (17) seem to have something to do with that in expression (11)? 
Do hypothetical relationships among expressions (18) (20) seem to suggest something?

$$
\begin{aligned}
1 & =\frac{\kappa T_{\boldsymbol{\mu} v}}{G_{\boldsymbol{\mu} v}+\Lambda g_{\boldsymbol{u} v}}, \\
& =\left(\sqrt{\frac{1+v / c}{1-v / c}}\right) \exp \left(\ln \left(\sqrt{\frac{1-v / c}{1+v / c}}\right)\right), \\
& =\mid \lim _{\boldsymbol{v} \rightarrow \infty}\left(\left.\left(\sqrt{\frac{1+v / c}{1-v / c}}\right) \exp \left(\ln \left(\sqrt{\frac{1-v / c}{1+v / c}}\right)\right)\right|^{2} .\right.
\end{aligned}
$$

\section{Conclusions}

This study suggests a hypothesis that Bondi K-factor has something to do with some natural phenomena, but the hypotheses suggested in this report should be severely criticized.

\section{REFERENCES}

Blackman, V. H. 1919 The compound interest law and plant growth. Ann. Bot., 33: 353-360

Bondi, H. 1964 Relativity and Common Sense (Doubleday and Company Inc.,). Translation into Japanese by T. Yamanouchi for publication (1967), Kawade Shobo Publishers, Tokyo.

Brody, S. 1945 Time relations of growth of individuals and populations. In "Bioenergetics and growth - with special reference to the efficiency complex in domestic animals", Reinhold Publishing Corporation, New York, pp. 484-574

Lavenda, B. H. 2000 Special relativity via modified Bessel functions. Z. Naturforsch., 55a: 745-753

Shimojo, M. 2011a Symmetry in motion in Euler's formula and its breakdown in hyperbolic function and growth function. $J$. Fac. Agr, Kyushu Univ., 56: 79-81

Shimojo, M. 2011b Exponential function, Bondi K-factor and imaginary unit. J. Fac. Agr, Kyushu Univ., 56: 285-286

Shimojo, M. and Y. Nakano 2013a An investigation into relationships between exponential functions and some natural phenomena. J. Fac. Agr., Kyushu Univ., 58: 51-53

Shimojo, M. and Y. Nakano 2013b Napier's constant, imaginary unit, circular constant and some natural phenomena. J. Fac. Agr, Kyushu Univ., 58: 281-285

Shimojo, M. 2014 Incorporation of Bondi K-factor into exponential function, and some related problems. J. Fac. Agr. Kyushu Univ., 59: 93-95 